OPEN ACCESS

Edited by:

Bin Yu,

Government of Canada, Canada

Reviewed by:

Jiankai Zhang,

Lanzhou University, China

*Correspondence:

Huiping Yan

yanhp2009@gmail.com

Specialty section:

This article was submitted to

Atmospheric Science,

a section of the journal

Frontiers in Earth Science

Received: 23 September 2020 Accepted: 14 December 2021

Published: 18 February 2021

Citation:

Zhou Y, Yan H and Luo J-J (2021) Impacts of Amazon Fire Aerosols on the Subseasonal Circulations of the Mid-High Latitudes.

Front. Earth Sci. 8:609554. doi: 10.3389/feart.2021.609554

\section{Impacts of Amazon Fire Aerosols on the Subseasonal Circulations of the Mid-High Latitudes}

\author{
Yu Zhou, Huiping Yan* and Jing-Jia Luo
}

Institute for Climate and Application Research, Key Laboratory of Meteorological Disaster, Ministry of Education/Joint International Research Laboratory of Climate and Environment Change/Collaborative Innovation Center on Forecast and Evaluation of Meteorological Disasters, Nanjing University of Information Science and Technology, Nanjing, China

The strong radiative effects of fire aerosols have been well accepted in the climate community. However, there have been few studies on the aerosol effects at a monthly to subseasonal range. We used the National Centers for Environmental Prediction (NCEP) reanalysis datasets and Community Atmosphere Model Version 5 (CAM5) to explore the impacts of Amazon fire aerosols on the subseasonal climate. With the reanalysis datasets, we found that most of the abnormal high emissions tended to happen more frequently/ intensely under a dry and warm condition during the La Niña years. And the composite analysis of the abnormal high emissions showed that there is a La Niña-like pattern of sea surface temperature anomalies (SSTA), precipitation, and circulation anomalies. To isolate the aerosol impacts from the SSTA, we removed the linear regressions of the Nino3.4 SST index, and found that significant anomalies in the pressure field still persisted in the midlatitude. Five wavetrains can be found in the mid-high latitudes of both hemispheres induced by Amazon fire aerosols. Through prescribing climatological mean SST and La Niña-like SSTA in CAM5 simulations respectively, we found that only the latter could reproduce the aerosol impact on circulation in the mid-high latitudes, i.e., five-wave anomalies, although with biased locations. This indicates that the Amazon wildfire aerosol impacts are highly coupled with the La Niña-like SSTA. This study emphasizes that Amazon fire aerosols indeed result in significant circulation anomalies in the mid-high latitudes and including fire aerosols may improve model forecasting skills at the monthly to subseasonal timescale.

Keywords: aerosol impact, subseasonal, circulation anomaly, wavetrain, La Niña SSTA

\section{INTRODUCTION}

The Amazon rainforest is located in the tropics, accounting for $40 \%$ of the global tropical forest area (Laurance et al., 2001; Aragão et al., 2014). Because it is the largest and most diverse tropical rainforest in the world, it is often called the "lung" of the Earth. The Amazon rainforest plays a major role in regulating the Earth's climate via the exchange of water, momentum, and carbon between the biosphere and atmosphere (Chambers et al., 2001; Werth and Avissar, 2002). However, through global warming and an increase in the frequency and intensity of droughts, the world's tropical forest may be turned into a more fire-prone ecosystem (Malhi et al., 2008). Recently, more fire events and more intense fires have occurred in the Amazon region (INPE 2020), which has attracted attention from society and scientific communities. 
Thus, the impacts of amazon fire on the climate system merits further understanding and investigation.

What is remarkable is that fires are also responsible for the emissions of large amounts of aerosol constituents. van der Werf et al. (2010) estimated for the period between 1997 and 2009 that, globally, the annual average carbon emissions caused by fire is 2.0 Pg.C.year ${ }^{-1}$, with South America contributing 15\%. Of this, about $8 \%$ appears to have been associated with forest fires, based on estimates from the Global Fire Emission Dataset (GFED3) product for South America. Despite the short lifetime of aerosols in the atmosphere, biomass-burning aerosols can have significant impacts on global and regional precipitation and atmospheric circulation (Ackerman et al., 2000; Tosca et al., 2013; Tosca et al., 2014). Aerosols affect the climate system in several ways, including the scattering and absorbing of solar radiation (direct effects) (Haywood and Boucher, 2000), as well as serving as cloud condensation nuclei and modifying cloud properties such as the cloud life cycle, their optical properties, and the precipitation activity of clouds (indirect effects) (Rosenfeld et al., 2014). In terms of direct effects, absorbing aerosols, which directly heats the atmosphere, may be particularly efficient at perturbing atmospheric circulation and precipitation due to its ability to increase tropospheric stability and perturb meridional temperature gradients (Shen and Ming, 2018).

Previous studies have shown that aerosols are linked to several circulation responses, including the southward shifts of the tropical rain belt (Allen, 2015), exciting robust drying in the northern edge of the Atlantic Inter-Tropical Convergence Zone (ITCZ) and in the Sahel (Rotstayn and Lohmann, 2002), weakening the South Asian Summer Monsoon season (Bollasina et al., 2011) and the Hadley circulation (Tosca et al., 2013). In addition, some studies suggest that aerosols can perturb the dominant modes of climate variability. For instance, Allen et al. (2014), found that anthropogenic aerosols can modify the Pacific Decadal Oscillation (PDO) and alter the width of the tropical belt. Similarly, Takahashi and Watanabe (2016) found that approximately one-third of the trade-wind intensification for 1991-2010 can be attributed to changes in sulfate aerosols. Booth et al. (2012) found that decadal-scale model predictions of the regional Atlantic climate would probably be improved by incorporating aerosol-cloud microphysical interactions and estimates of future concentrations of aerosols. Lou et al. (2019) found that increases in Black Carbon (BC) emissions from both the midlatitudes and Arctic weaken meridional temperature gradients and northward heat transport, and increase the frequency of extreme El Niño Southern Oscillation (ENSO) events. Meanwhile, the impact of aerosol particles may also be an important factor on accurate climate simulations. Fan et al. (2018) found that anthropogenic fine aerosols could be activated to form additional cloud droplets and latent heating in deep convective clouds and intensify deep convection.

Considering the short lifetime of aerosols in the atmosphere and the several month duration of amazon fire events, the significant of impacts of fire aerosols on the climate may range from seasonal to subseasonal scales. Benedetti and Vitart (2018) suggested that interactive aerosols have the capability of improving subseasonal predictions at a monthly scale in the season of spring/summer. This study focuses on the impacts of amazon fire aerosols on large-scale circulation at the subseasonal scale. This paper is organized as follows: the data, model, and numerical experiment are described in Methodology section. The analysis with the reanalysis datasets and CAM5 simulations are presented in Results section. Discussion and Conclusion section summarizes the main conclusions and discussion.

\section{METHODOLOGY}

\section{Data}

The Amazon region between $-20^{\circ} \mathrm{S}$ and $10^{\circ} \mathrm{N}$ and $80^{\circ} \mathrm{W}$ to $35^{\circ} \mathrm{W}$ was selected. Monthly biomass burning emissions from the Global Fire Emissions database version 4 (GFED v4, available at https://www.globalfiredata.org/) (van der Werf et al., 2017) with a horizontal resolution of $0.25^{\circ} \times 0.25^{\circ}$ from 1997 to 2016 were used. Geopotential height, wind field, and surface temperature data from NCEP/NCAR reanalysis data, precipitation data from the Global Precipitation Climatology Project (GPCP) (Adler et al., 2003), and Hadley Centre Sea Ice and Sea Surface Temperature dataset (HADISST) were employed. The Niño3.4 SST index (Kaplan et al., 1998) as an index of ENSO was also employed.

The statistical significance of the differences were calculated by Student's $t$-test in this study.

\section{Model Overview And Experiment Design}

In this study, we used the National Center for Atmospheric Research (NCAR) Community Earth System Model (CESM) version 1.2.1, with the Community Atmosphere Model version 5 (CAM5). The main physical parameterizations used were the Zhang-McFarlane deep convection scheme (Zhang and McFarlane, 1995), a mass flux scheme with convective inhibition closure for shallow convection (Park and Bretherton, 2009), a twomoment stratiform cloud microphysics scheme (Morrison and Gettelman, 2008) with ice supersaturation (Gettelman et al., 2010), and a diagnostic cloud fraction scheme for cloud microphysics and macrophysics. Aerosols were represented by the 3-mode (Aitken, accumulation and coarse mode) Modal Aerosol Module (MAM3, Liu et al. 2012) scheme.

Two groups of experiments were performed to evaluate the amazon fire aerosol effects. One utilized the default Intergovernmental Panel on Climate Change (IPCC) AR5 dataset emission data (Lamarque et al., 2010) (AR5 experiment), and the other was performed using additional wildfire aerosol emissions (only black carbon, organic carbon, and sulfur dioxide are considered) from the GFED v4 monthly dataset over the Amazon region (FIRE experiment). GFED v4 monthly emissions from 2005 to 2015 were prescribed, and the vertical distribution of fire emissions was consistent with the IPCC AR5 emission dataset. Other forces (e.g., SST, anthropogenic aerosol emissions) and physical parameterization of all these experiments were kept the same. All simulations were performed at a resolution of $0.9^{\circ} \times 1.25^{\circ}$ with 30 vertical levels. The differences between the FIRE and AR5 

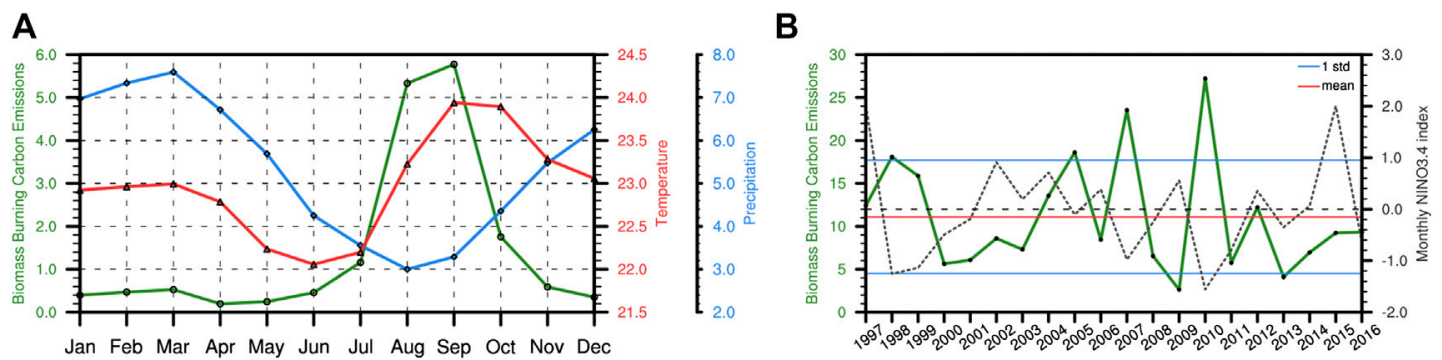

FIGURE 1 | (A) the annual cycle of biomass burning emission (green, $\mathrm{g} \mathrm{C} / \mathrm{m}^{2}$ ), total precipitation (blue, $\mathrm{mm} /$ day), and temperature (red, C) over Amazon during 1997-2016. (B) the time series of the Amazon carbon emissions (green soild line, g C/ $\mathrm{m}^{2}$ ) and Nino3.4 index (dash line, K) of the Amazon fire season (August and September) from 1997 to 2016. Red horizontal line: the mean value of the time series. Blue line: one standard deviation above and below the mean value.
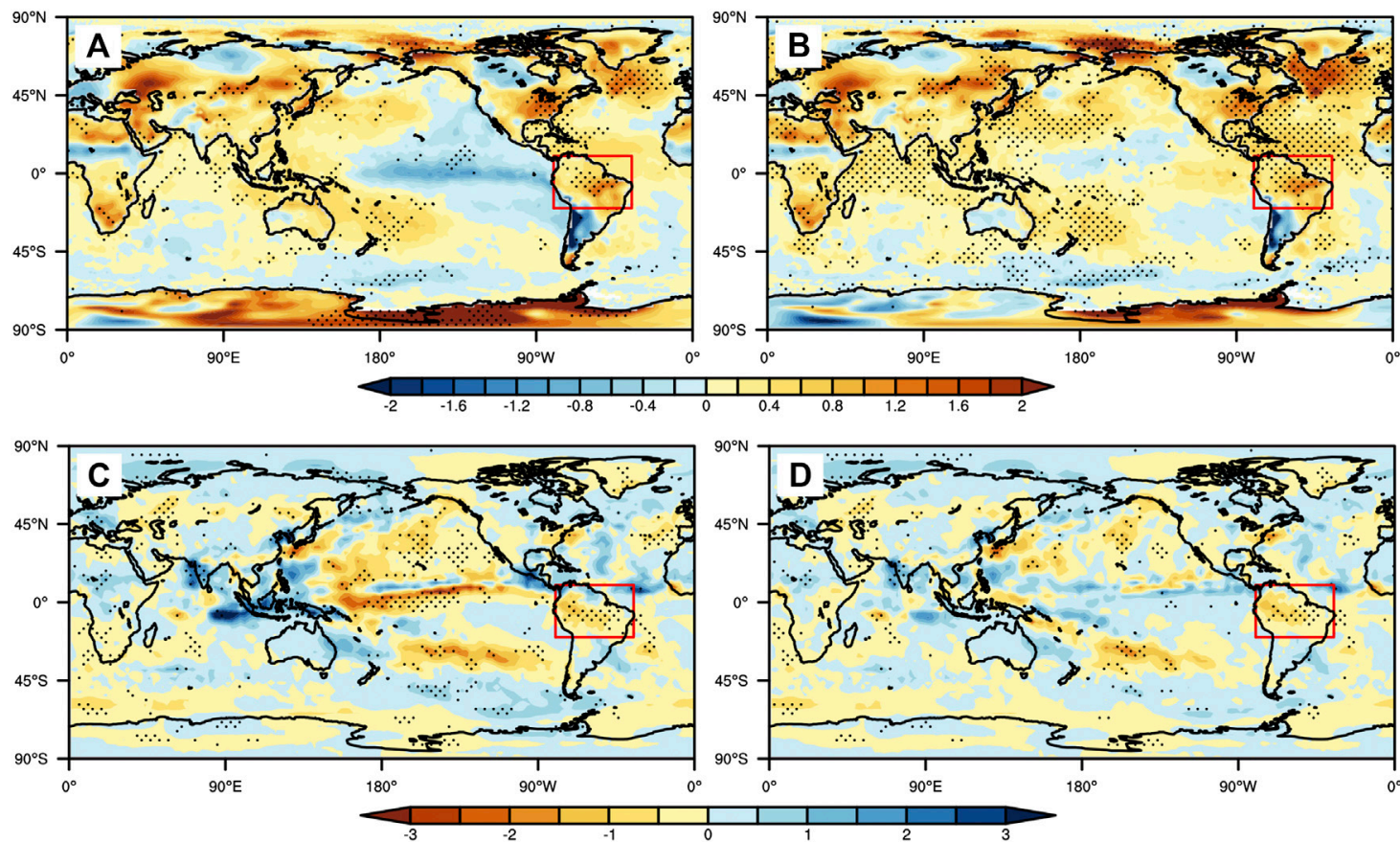

FIGURE 2 | (A) Composited surface air temperature anomalies of fire season (August and September) in high emission years against the average over 1997-2016; (B) same as (A) but excluding the impacts of Sea Surface Temperature anomalies (SSTA) by removing the linear regressions of Nino3.4 index; (C) and (D) are same as (A) and (B) respectively, but for precipitation. Cross symbols denote significance at $90 \%$ confidence level, based on Student t-test. Units are ${ }^{\circ} \mathrm{C}$, $\mathrm{mm}_{\text {day }}{ }^{-1}$ for temperature and precipitation, respectively.

experiments can be taken as the impact of Amazonian biomass aerosols.

Since the Amazon fire activities are highly related to the La Niña-like pattern SSTAs (see Analysis With Observation section), we performed another couple of experiments (La Niña-AR5 and La Niña-FIRE) with anomalous La Niña-like SST being prescribed over the Pacific Ocean. The anomalous (La Niñalike pattern) SST were derived from years with strong Amazon fire activities. The simulations were conducted from 2005 to 2015 (i.e., for 11 years) with prescribed SST and sea ice. The last 10 years 2006-2015 were then analyzed.

To evaluate the simulation of the circulation field in the fire anomaly years, a 10 years AMIP simulation was conducted with the default IPCC AR5 emission data and yearly updated SST data. And the years of the simulated circulation anomalies of La Niña were compared with the corresponding period of NCEP data to evaluate the model performance.

\section{RESULTS}

\section{Analysis With Observations}

With the GFED data, we analyzed the annual and interannual variability of the biomass-burning carbon emissions over the Amazon region from 1997 to 2016. Figure 1A shows the annual cycle of total precipitation, temperature, and biomass-burning 
carbon emissions over the Amazon. There was a significant seasonal cycle in the fire emissions. It tended to intensify from July, and peak in August and September. At the same time, these months also corresponded to the minimum in precipitation and a significant increase in temperature, which favored the occurrence of fire events. As August and September are the major fire emission months over the Amazon, in the following we took these 2 months as the fire season and focused on the analysis in this fire season.

Figure 1B shows the time series of the Amazon carbon emissions and the Nino3.4 index of the Amazon fire season (August and September). Significant interannual variability in the fire emissions can be found. The mean of fire emissions over $1997-2016$ was $11.11 \mathrm{~g} \cdot \mathrm{C} / \mathrm{m}^{2}$ and the standard deviation was $6.60 \mathrm{~g} \cdot \mathrm{C} / \mathrm{m}^{2}$. Thus, the abnormally high emission years (greater than 1 std) were $1998,2005,2007$, and 2010. It is notable that moderate to strong La Niña events also occurred in these years except 2005. Comparing Amazon fire emissions with the Nino3.4 index, these abnormally high emissions concurred with the negative Nino3.4 index except in the year of 2005, and the correction coefficient of -0.39 was significant at a 0.1 statistical level. The negative Nino3.4 index (La Niña-like SSTA) accompanied with dry and warm air in the East Pacific would enhance the strength of the fire event and increase the fire emission, and that explains why the abnormally high fire emission concurred with the low value of the Nino3.4 index. However, the low value of Nino3.4 does not always responding to a high emission (for example, 2011). This is probably because wildfire events are not only affected by meteorological conditions, but are also highly related to human activities, such as the burning of forests to clear land for agriculture and grazing (van der Werf et al., 2017).

The years with high Amazon fire emissions were selected and composited to analyze the abnormal climate characteristics (Figure 2). In the Tropical Pacific, the temperature (Figure 2A) and precipitation (Figure 2C) anomalies had a $\mathrm{La}$ Niña-like pattern of characteristics: there was a cold tongue in the equatorial central and eastern Pacific, and the temperature in the Amazon and Africa was relatively high. There were significantly negative anomalies of precipitation along the coast of Peru and the equatorial Pacific, whereas positive anomalies of precipitation were found in Indonesia. In the mid-high latitudes, negative anomalies in precipitation can be seen in the southeastern part of East Asia and the central part of the South Pacific, and no significant anomalies were seen in other regions. But the anomalies of temperature were quite obvious. In particular, there was significant anomalous warming of $\sim 1.5^{\circ} \mathrm{C}$ in southern North America, central Europe, and southern Africa. There were positive anomaly centers in northern South America and southern North America.

Considering that the strong fire years mostly corresponded to La Niña incident occurring years, the anomaly in precipitation and circulations may include the influence of tropical Pacific Sea Surface Temperature anomalies (SSTA), which are usually thought to have impacts at long time scales. To isolate the impacts of fire aerosols from the SSTA, we excluded the impacts of SSTA by removing the linear regressions of the
Nino3.4 index from the composited anomalies (see Figures 2B, D). Clearly, the characteristics of the Pacific Ocean changed significantly. In the tropics, the dry and cold anomaly almost disappeared when the Nino3.4 contribution was removed, but the positive anomaly in surface air temperature in the Amazon and Southern Africa persisted. And in the mid-high latitudes, the previous features were retained with slightly reduced magnitudes.

From the circulation anomaly of abnormal emission years in the Amazon fire season (Figures 3A,C,E), we found that the most significant feature in the low and middle troposphere (Figures 3C,E) was the dipole pattern over the South Pacific and Southern Ocean with a positive anomaly in the north and a negative anomaly in the south. This dipole pattern can be also found at $200 \mathrm{hPa}$, but the magnitude compared to other anomalies at the same level was comparable, indicating that the energy was dispersed at the upper level. A dipole pattern also existed in the North Pacific but with a small wave length. Globally speaking, the dipole anomalies in the North Pacific and South Pacific were quasi-symmetric. The negative (although not significant) height centers at the subtropical Pacific (Figure 3A) combined with the dipoles were a Gilltype response (Gill, 1980) to the cold tongue over the central and eastern Pacific.

Besides the most significant dipole anomalies, in the mid-high latitudes, there were wave train patterns of anomalies at $200 \mathrm{hPa}$ (Figure 3A), with five waves in the Northern Hemisphere and three waves in the Southern Hemisphere. In the Northern Hemisphere, the five positive anomaly centers were located at Central Europe, Central East Asia, the Aleutian Islands, southern North America, and the Azores. Similar anomalies have been found in previous studies (Shaman and Tziperman, 2005, Zhang et al., 2015a, Zhang et al., 2015b), in which such anomalies were induced by the SSTA in the Pacific instead of aerosols. In the Southern Hemisphere, the three positive anomaly centers were located in southern Africa, the Central South Pacific, and Southwest Atlantic, respectively. All the positive abnormal centers passed the significance test.

When the linearized SSTA impacts were removed, the dipole anomalies over the South Pacific were significantly weakened, indicating that the SSTA over the central Pacific did indeed have an impact on the composted circulations. But the anomalies over the east of South America and over the North Pacific persisted in the entire troposphere (Figures 3B,D,F). And in the upper troposphere, the wave trains in the North Hemisphere were still clear. And, the pattern over the mid-high latitude of the Southern Hemisphere changed. There were five positive centers in the mid-high latitude of the Southern Hemisphere (Figure 3B) when the linearized SSTA impacts were removed. It means that the Amazon fire aerosols did indeed have a significant impact and induced five-wave anomalies in the mid-high latitudes. Further, some of the impacts of amazon fire aerosols (i.e., the 5-wavetrain anomalies in the Southern Hemisphere) may be overwhelmed by the SSTA impacts. This is somewhat different from previous studies that found that the anomalies in the Northern mid-high latitudes were thought to be induced by the SSTA in the Pacific though a Rossby wave (Shaman and Tziperman, 2005, Zhang 

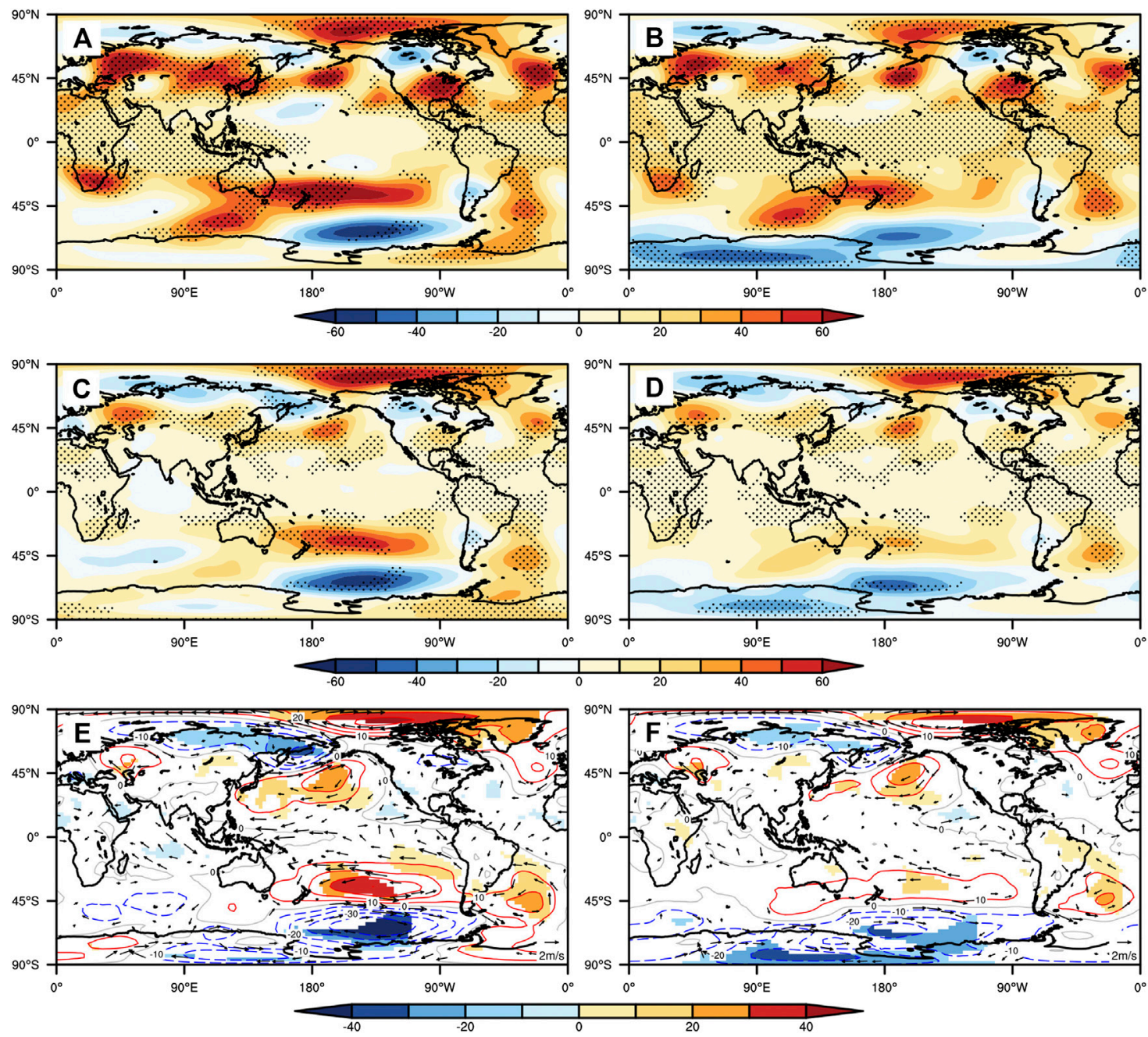

FIGURE 3 | Same as Figure 1 but for the circulation anomaly (color shading shows geopotential height, units: gpm; vector is wind, units: $\mathrm{m} / \mathrm{s}$ ). From top to bottom are 200,500 , and $850 \mathrm{hPa}$, respectively. Cross symbols in (A-D) denote significance at a $90 \%$ confidence level. In (E,F) the height field that passed the $t$-test is represented by a contour map, and only the wind field that passed the $t$-test is drawn.

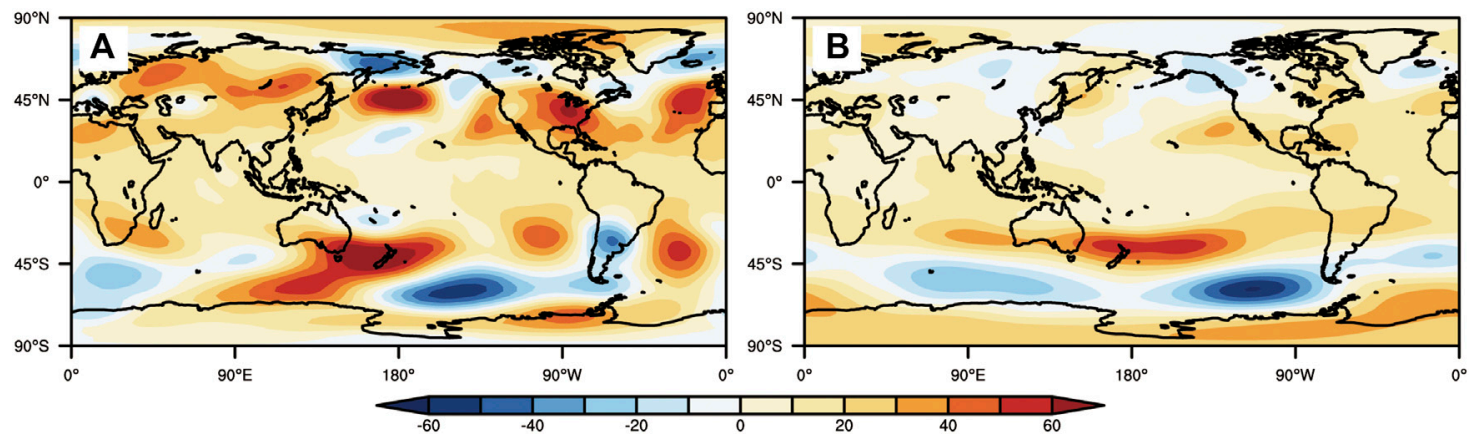

FIGURE 4 | Composited circulation anomaly of high emission years in the fire season with (A) NCEP data and (B) AMIP experiments at 200 hPa (color shading shows geopotential height, units: gpm). Note: since only 1998 and 2005 are included in the AMIP 10 years run, in the observations here these 2 years are taken as the Amazon high emission years. 

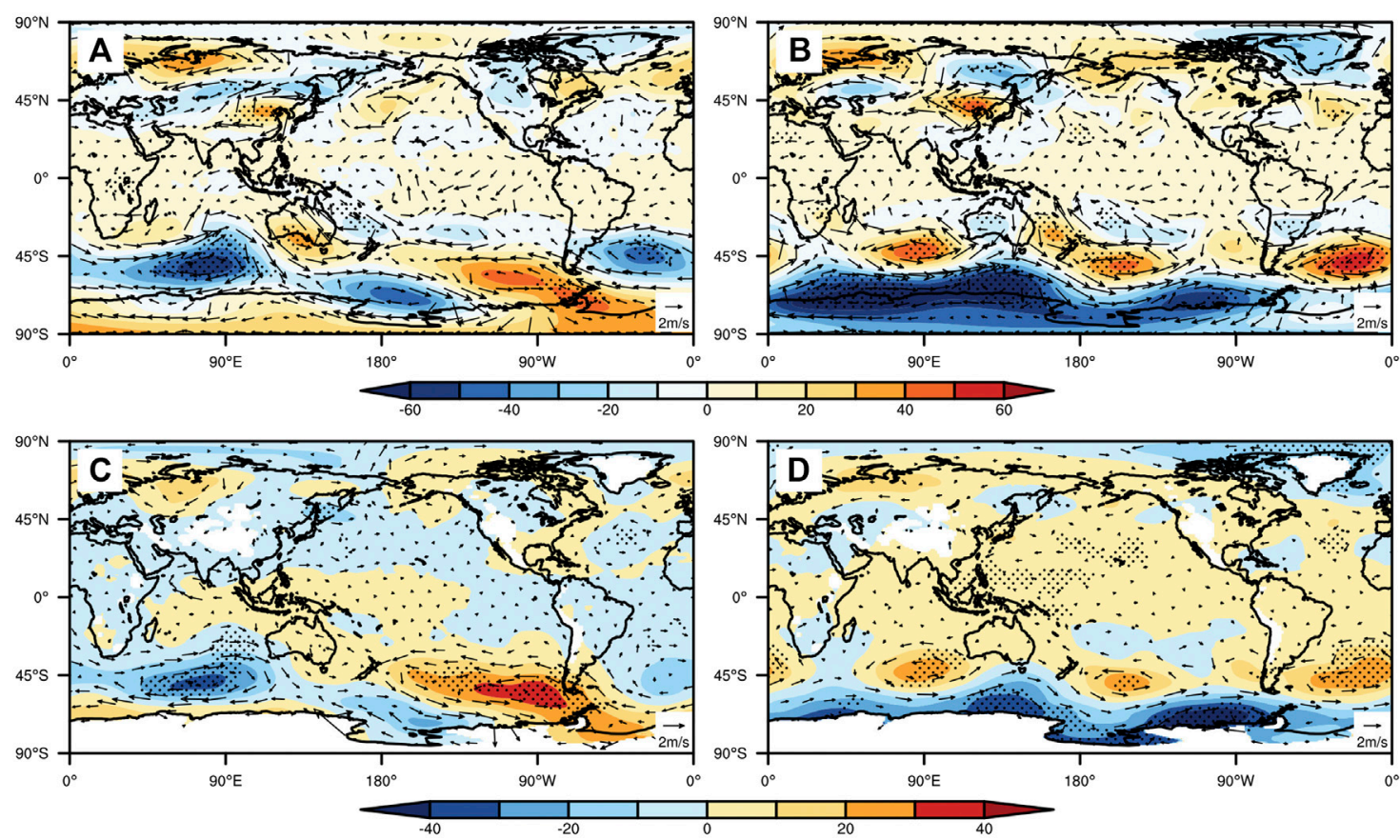

FIGURE 5 | Circulation anomaly at 200hPa of (A) Climatology SST Simulation and (B) La Niña SST (over Pacific Ocean) simulation in fire season. (C) and (D) are same as (A) and (B) respectively, but for $850 \mathrm{hPa}$. Color shading is geopotential height, units: gpm; vector is wind, units: $\mathrm{m} / \mathrm{s}$. Cross symbols denote significance at $90 \%$ confidence level, based on Student t-test.

et al., 2015a, Zhang et al., 2015b). It means that the impacts of aerosols may resemble the SSTA and provide some predictability for the monthly-to-seasonal climate prediction.

\section{Analysis With CAM5 Simulation Model Evaluation}

A synthetic analysis on the circulation field over the abnormally high emission years was carried out to compare them with the AMIP simulation and evaluate the model performance (Figure 4). Generally speaking, the CAM5 could represent the circulation anomaly induced by La Niña-like SSTA. The dipole pattern over the South Pacific and anomalies on both sides of the subtropical Pacific were well simulated. But the dipole position was slightly biased. Note here, there was a distinct difference in the mid-high latitudes, especially in the Arctic and Antarctic. In the Arctic, the simulated anomaly center was located at the Barents Sea and Kara Sea while in the observation it was centered at the Northwestern Passages and Baffin Bay. And the observed positive-bridge pattern anomaly from $90^{\circ} \mathrm{E}$ Antarctic to New Zealand was not represented in the simulations, and over the whole South Ocean all of the anomalies were negative. These discrepancies are possibly caused by the bias in the basic flow, i.e., the westerly jet (too strong, figure not shown), as the anomalies are highly dependent on the location of the westerly jet (Shaman and Tziperman, 2005, Zhang et al., 2015a, Zhang et al., 2015b). These difference between the reanalysis and model results indicate that there are still large deficiencies in the CAM5 model in simulating the polar region and South Ocean. We know this may affect the simulated aerosol impacts in the mid-high latitudes, but fortunately our experiments successfully reproduced some significant features that were observed in the reanalysis data (i.e., the five wave trains in the mid-high latitude in the Southern Hemisphere, see Analysis on the Model Simulated Aerosol Impacts on Circulations section).

\section{Analysis on the Model Simulated Aerosol Impacts on Circulations}

As we mentioned in Methodology, we conducted two groups of experiments, one with prescribed climatology SST (FC5 experiments), and the other with an La Niña-like pattern SSTA (La Niña experiments), and both of them had two 10years simulations with/without Amazon fire aerosols. The circulation anomalies induced by Amazon fire aerosols over the fire season (August and September) were analyzed (Figure 5). It can be seen that there were significant anomalies in the mid-high latitudes in both experiments. In the mid-high latitudes of the Northern Hemisphere, there were five waves in both experiments, but the locations of the anomalous centers shifted when compared with the observations.

Clearly, the impacts of Amazon fire aerosols on circulation in these two groups of experiments show large discrepancies in the mid-high latitudes in the Southern Hemisphere. For example, the anomaly centered at the southeast of South America, was negative in the FC5 experiments (Figure 5A) meanwhile it was positive when a La Niña-like pattern of SSTA was applied (Figure 5B). And there were five waves in the South Ocean in the La Niña experiment 

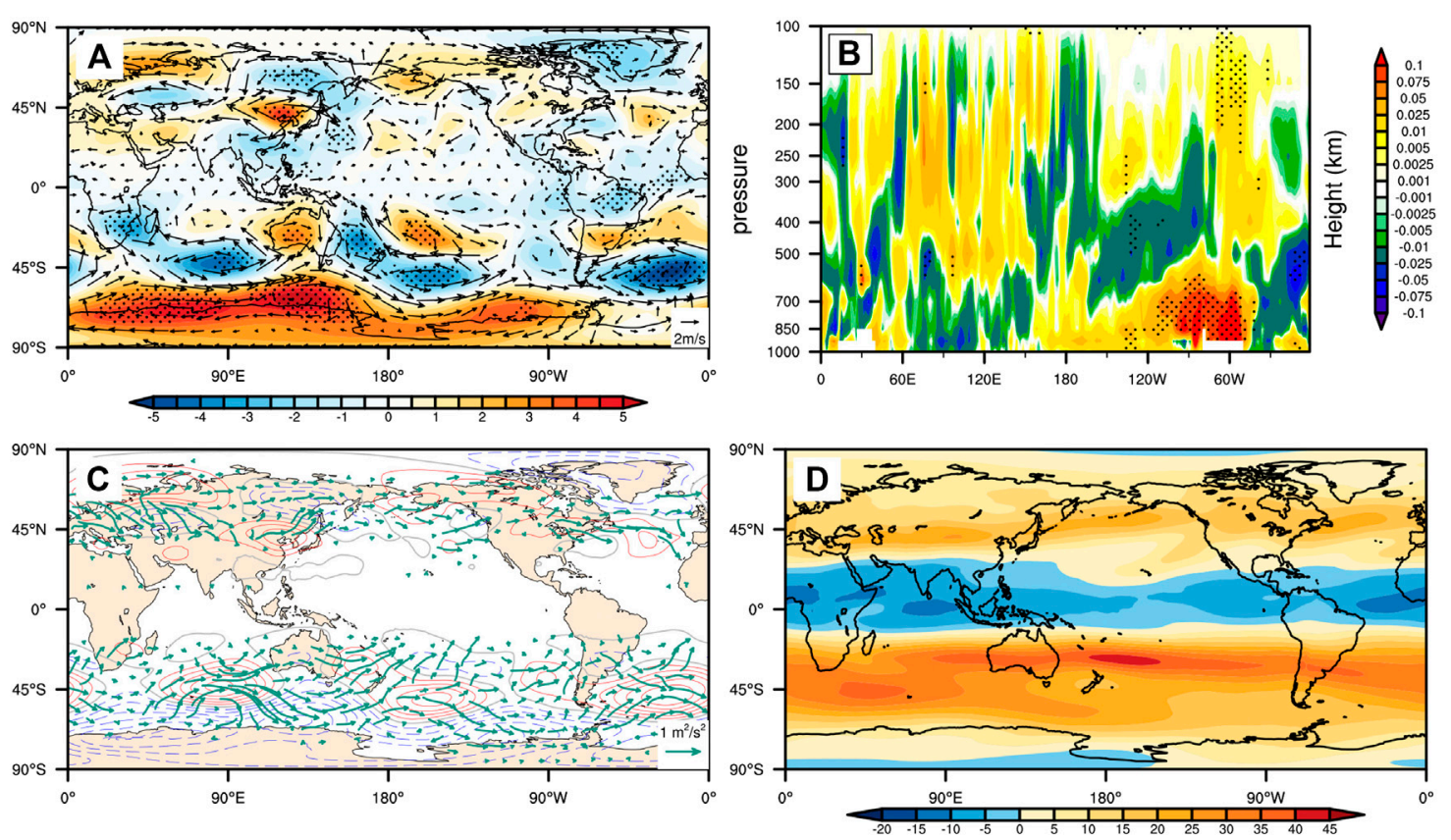

FIGURE 6 | (A) Stream function anomaly (color shading, units: $10^{6} \mathrm{~m}^{2} / \mathrm{s}$ ) and winds fields (vectors, units: $\mathrm{m} / \mathrm{s}$ ) at $200 \mathrm{hPa}$ of the La Niña experiment. (B) Pressurelongitude cross-section of the solar heating rate anomaly (color shading, units: $\mathrm{K} / \mathrm{s}$ ) over $10^{\circ} \mathrm{S}-0$. (C) Wave activity flux (green vectors, units: $\mathrm{m}^{2} / \mathrm{s}^{2}$ ) and geopotential height anomaly (contours, units: gpm) of the La Niña experiment. (D) Zonal winds (color shading, units: m/s) at 300 hPa of the La Niña experiment without additional aerosols. Cross symbols in $\mathbf{( A , B )}$ denote significance at a $90 \%$ confidence level.

while there were only three waves in the FC5 experiment at $200 \mathrm{hPa}$. Further, the anomalies in the Antarctic in the La Niña experiment were significantly negative while in the FC5 experiment they were slightly positive. Compared with the observations shown in Figure 3B, the La Niña experiments reproduced the 5-wavetrain circulation anomalies induced by Amazon fire aerosols with biased locations of some anomalous centers.

The large discrepancies between the FC5 and La Niña experiments may be due to the difference of the mean state of the experiments, i.e., the forcing of La Niña-like SSTA. The La Niña-like SSTA would concurrent with enhanced Walker Circulation, enhancing downwelling and reducing precipitation in the East Pacific. These characteristics would enlarge the spread of fire aerosols (which can be seen from the changes in AOD, figure not shown here) because of the strong easterly wind in the low troposphere, and downwelling transport of the heated air induced by absorbing aerosols downward over the East Pacific. This deduction can be seen from the slightly negative anomalies in FC5, and the weak positives in La Niña over the East Pacific at the low troposphere (Figures 5C,D). Another interesting thing was that at $200 \mathrm{hPa}$ there were easterly winds and positive height anomalies in both experiments. Such easterly wind anomalies may weaken La Niña and result in a positive feedback on ENSO events, which may need further investigation. In summary, the contrast difference between FC5 and La Niña experiments indicate that the Amazon aerosol effects were strongly dependent on the mean climate state.

We further analyzed the changes of the solar radiative heating rate induced by Amazon fire aerosols (Figure 6B). It can be found that between 120 and $60^{\circ} \mathrm{W}$, there were significant solar radiative heating with a maximum of greater than $0.1 \mathrm{~K} /$ day at the low troposphere. Such strong radiative heating is caused by the combined effects of the reflection of low-level stratocumulus clouds and the absorbing aerosols (Lu et al., 2018) emitted by Amazon fires. Above the significant warming, a weak cooling above the west of $60^{\circ} \mathrm{W}$, and a slight warming of the tropopause east of $60^{\circ} \mathrm{W}$ also occurred. This heating profile was responsible for the anticyclone over the east Amazon (Figure 6A), which emanated Rossby waves that propagated southeastward (Figure 6C), one branch turning back to the equator, and the other going southeastward to the South Ocean (the strong positive height anomaly at the southeast of South America in Figure 5D), and then propagating eastward along the South Ocean. Interestingly, during the propagation of the Rossby wave over the South Ocean, the wave energy was transported in both meridional directions, the northward wave energy joined into the westerly jet (Figure 6D), and formed the short-wave centers at $30^{\circ} \mathrm{S}$ (Figure 6D), and the southward energy was refracted back by Antarctica, forming the winding wave trains in the mid-high latitudes. For those wave trains in the Northern Hemisphere, since most anomalies were not statistically significant, we will not discuss them further.

\section{DISCUSSION AND CONCLUSION}

In this study, we use GFED data to analyze the fire emissions over the Amazon, and found significant annual and interannual cycles. 
Amazon fire emissions always peak at August and September, i.e., the dry season. And most of the abnormally high emission years were accompanied with moderate to strong La Niña events. Thus, the characteristics of the abnormally high emission years show significant La Niña-like patterns in SSTA, precipitation, and circulations. After removing the influence of SSTA through linear regression, significant anomalies in circulation in the mid-high latitudes persisted. And five waves could be found in the mid-high latitudes of both hemispheres.

By comparing the two groups of with/without Amazon fire aerosol emissions coupled with prescribed climatology SST and prescribed a La Niña-like pattern of SSTA, we found that only the latter could reproduce the 5-wavetrain circulation anomalies like the reanalysis data with biased locations. The difference in these two experiments suggest that the impacts of aerosols are highly coupled with the mean state of the climate. With the La Niña-like SSTA, the significant warming caused by the Amazon fire aerosols at the low troposphere induced Rossby waves, which propagated southeastward and formed 5-wavetrain significant circulation anomalies over the South Ocean.

When comparing the model-simulated aerosol effects with the reanalysis data, there were some large discrepancies, which may be due to several reasons. First, the performance of the CAM5 model over the South Ocean and polar regions was poor, which would greatly limit the capability of the model to reproduce the aerosol effects. Further, the locations of the anomaly centers highly depended on the basic flow (Hoskins and Ambrizzi, 1993), and the too cold Antarctic and the overestimated westerly jet stream may be responsible for the shifted anomaly centers. Second, here we only applied the SSTA in the tropical Pacific, the anomalous circulation in other regions and other signals such as sea ice, may also have great impacts on regulating the circulation. Third, during the analysis of observations, we only removed the linear regression impacts of Nino3.4 SST, there may be some nonlinear impacts of SSTA on the mid-high latitudes, which would contribute to the difference between model simulations and reanalysis.

\section{REFERENCES}

Ackerman, A. S., Toon, O. B., Stevens, D. E., Heymsfield, A. J., Ramanathan, V., and Welton, E. J. (2000). Reduction of tropical cloudiness by soot. Science 288 (5468), 1042-1047. doi:10.1126/science.288.5468.1042

Adler, R. F., Huffman, G. J., Chang, A., Ferraro, R., Xie, P.-P., Janowiak, J., et al. (2003). The version-2 global precipitation climatology Project (GPCP) monthly precipitation analysis (1979-present). J. Hydrometeorol. 4 (6), 1147-1167. doi:10.1175/1525-7541(2003)004<1147:Tvgpcp >2.0.Co

Allen, R. J. (2015). A 21st century northward tropical precipitation shift caused by future anthropogenic aerosol reductions. J. Geophys. Res.: Atmos. 120 (18), 9087-9102. doi:10.1002/2015jd023623

Allen, R. J., Norris, J. R., and Kovilakam, M. (2014). Influence of anthropogenic aerosols and the Pacific Decadal Oscillation on tropical belt width. Nat. Geosci. 7 (4), 270-274. doi:10.1038/ngeo2091

Aragão, L. E., Poulter, B., Barlow, J. B., Anderson, L. O., Malhi, Y., Saatchi, S., et al. (2014). Environmental change and the carbon balance of Amazonian forests. Biol. Rev. 89 (4), 913-931. doi:10.1111/brv.12088

Benedetti, A., and Vitart, F. (2018). Can the direct effect of aerosols improve subseasonal predictability? Mon. Weather Rev. 146 (10), 3481-3498. doi:10. 1175/mwr-d-17-0282.1
Here in this study, we would like to emphasize that aerosols may have significant impacts on the climate of the mid-high latitudes. The five-wave anomalies pattern in observation and in simulations in the mid-high latitudes confirmed it. As the relative short lifetime of aerosols and the 2-month long fire season, these affects are at the range of monthly to subseasonal scales. The inclusion of fire aerosols impacts may be helpful in the subseasonal forecasts.

\section{DATA AVAILABILITY STATEMENT}

The raw data supporting the conclusion of this article will be made available by the authors, without undue reservation.

\section{AUTHOR CONTRIBUTIONS}

YZ conducted all the simulations, did the analysis, and composed the first draft of this manuscripts. HY designed the experiments, guided YZ to do the analysis, and modified the draft. JL proposed the initial idea on the impacts of Amazon fire aerosols. All authors agree on these contributions and there are no conflicts.

\section{FUNDING}

This work is supported by National Natural Science Foundation of China (NSFC) Grant 42030605 and NSFC42005115.

\section{ACKNOWLEDGMENTS}

The authors would like to acknowledge the use of computational resources at Supercomputing Center of Nanjing University of Information Science and Technology.

Bollasina, M. A., Ming, Y., and Ramaswamy, V. (2011). Anthropogenic aerosols and the weakening of the south asian summer Monsoon. Science 334 (6055), 502. doi:10.1126/science.1204994

Booth, B. B., Dunstone, N. J., Halloran, P. R., Andrews, T., and Bellouin, N. (2012). Aerosols implicated as a prime driver of twentieth-century North Atlantic climate variability. Nature 484 (7393), 228-232. doi:10.1038/ nature 10946

Chambers, J. Q., Higuchi, N., Tribuzy, E. S., and Trumbore, S. E. (2001). Carbon sink for a century. Nature 410 (6827), 429. doi:10.1038/35068624

Fan, J., Rosenfeld, D., Zhang, Y., Giangrande, S. E., Li, Z., Machado, L. A. T., et al. (2018). Substantial convection and precipitation enhancements by ultrafine aerosol particles. Science 359 (6374), 411-418. doi:10.1126/ science.aan 8461

Gettelman, A., Liu, X., Ghan, S. J., Morrison, H., Park, S., Conley, A. J., et al. (2010). Global simulations of ice nucleation and ice supersaturation with an improved cloud scheme in the Community Atmosphere Model. J. Geophys. Res.: Atmos. 115, D18216. doi:10.1029/2009jd013797

Gill, A. E. (1980). Some simple solutions for heat-induced tropical circulation. Q. J. R. Meteorol. Soc. 106, 447-462. doi:10.1002/qj.49710644905

Haywood, J., and Boucher, O. (2000). Estimates of the direct and indirect radiative forcing due to tropospheric aerosols: a review. Rev. Geophys. 38 (4), 513-543. doi:10.1029/1999rg000078 
Hoskins, B. J., and Ambrizzi, T. (1993). Rossby wave propagation on a realistic longitudinally varying flow. J. Atmos. Sci. 50, 1661-1671. doi:10.1175/15200469(1993)050<1661:RWPOAR>2.0.CO;2

Kaplan, A., Cane, M. A., Kushnir, Y., Clement, A. C., Blumenthal, M. B., and Rajagopalan, B. (1998). Analyses of global sea surface temperature 1856-1991. J. Geophys. Res.: Oceans 103 (C9), 18567-18589. doi:10.1029/97jc01736

Lamarque, J.-F., Bond, T. C., Eyring, V., Granier, C., Heil, A., Klimont, Z., et al. (2010). Historical (1850-2000) gridded anthropogenic and biomass burning emissions of reactive gases and aerosols: methodology and application. Atmos. Chem. Phys. 10 (15), 7017-7039. doi:10.5194/acp10-7017-2010

Laurance, W. F., Cochrane, M. A., Bergen, S., Fearnside, P. M., Delamônica, P., Barber, C., et al. (2001). Environment-the future of the Brazilian amazon. Science 291 (5503), 438-439. doi:10.1126/science.291. 5503.438

Liu, X., Easter, R. C., Ghan, S. J., Zaveri, R., Rasch, P., Shi, X., et al. (2012). Toward a minimal representation of aerosols in climate models: description and evaluation in the Community Atmosphere Model CAM5. Geosci. Model Dev. 5 (3), 709-739. doi:10.5194/gmd-5-709-2012

Lou, S., Yang, Y., Wang, H., Lu, J., Smith, S. J., Liu, F., et al. (2019). Black carbon increases frequency of extreme ENSO events. J. Clim. 32 (23), 8323-8333. doi:10.1175/jcli-d-19-0549.1

Lu, Z., Liu, X. H., Zhang, Z. B., Zhao, C., Meyer, K., Rajapakshe, C., et al. (2018). Biomass smoke from southern Africa can significantly enhance the brightness of stratocumulus over the southeastern Atlantic Ocean. PNAS. 115, 2924-2929. doi:10.1073/pnas.1713703115

Malhi, Y., Roberts, J. T., Betts, R. A., Killeen, T. J., Li, W., and Nobre, C. A. (2008). Climate change, deforestation, and the fate of the amazon. Science 319 (5860), 169-172. doi:10.1126/science. 1146961

Morrison, H., and Gettelman, A. (2008). A New two-moment bulk stratiform cloud microphysics scheme in the community atmosphere model, version 3 (CAM3). Part I: description and numerical tests. J. Clim. 21 (15), 3642-3659. doi:10.1175/ 2008jcli2 105.1

Park, S., and Bretherton, C. S. (2009). The university of Washington shallow convection and moist turbulence schemes and their impact on climate simulations with the community atmosphere model. J. Clim. 22 (12), 3449-3469. doi:10.1175/2008jcli2557.1

Rosenfeld, D., Sherwood, S., Wood, R., and Donner, L. (2014). Atmospheric science. Climate effects of aerosol-cloud interactions. Science 343 (6169), 379-380. doi:10.1126/science. 1247490

Rotstayn, L. D., and Lohmann, U. (2002). Tropical rainfall trends and the indirect aerosol effect. J. Clim. 15 (15), 2103-2116. doi:10.1175/1520-0442(2002) 015<2103:Trtati $>2.0 . C 0 ; 2$

Shaman, J., and Tziperman, E. (2005). The effect of ENSO on Tibetan Plateau snow depth: a stationary wave teleconnection mechanism and implications for the South Asian monsoons. J. Clim. 18, 2067-2079. doi:10.1175/JCLI3391.1
Shen, Z., and Ming, Y. (2018). The influence of aerosol absorption on the extratropical circulation. J. Clim. 31 (15), 5961-5975. doi:10.1175/jcli-d-170839.1

Takahashi, C., and Watanabe, M. (2016). Pacific trade winds accelerated by aerosol forcing over the past two decades. Nat. Clim. Change. 6 (8), 768-772. doi:10. 1038/nclimate2996.

Tosca, M. G., Diner, D. J., Garay, M. J., and Kalashnikova, O. V. (2014). Observational evidence of fire-driven reduction of cloud fraction in tropical Africa. J. Geophys. Res.: Atmos 119 (13), 8418-8432. doi:10. 1002/2014jd021759

Tosca, M. G., Randerson, J. T., and Zender, C. S. (2013). Global impact of smoke aerosols from landscape fires on climate and the Hadley circulation. Atmos. Chem. Phys. 13 (10), 5227-5241. doi:10.5194/acp13-5227-2013

van der Werf, G. R., Randerson, J. T., Giglio, L., Collatz, G. J., Mu, M., Kasibhatla, P. S., et al. (2010). Global fire emissions and the contribution of deforestation, savanna, forest, agricultural, and peat fires (1997-2009). Atmos. Chem. Phys. 10 (23), 11707-11735. doi:10.5194/acp-10-11707-2010

van der Werf, G. R., Randerson, J. T., Giglio, L., van Leeuwen, T. T., Chen, Y., Rogers, B. M., et al. (2017). Global fire emissions estimates during 1997-2016. Earth Syst. Sci. Data. 9 (2), 697-720. doi:10.5194/essd-9-697-2017

Werth, D., and Avissar, R. (2002). The local and global effects of Amazon deforestation. J. Geophys. Res.: Atmos 107 (D20), 58. doi:10.1029/ 2001jd000717

Zhang, G. J., and McFarlane, N. A. (1995). Sensitivity of climate simulations to the parameterization of cumulus convection in the Canadian climate centre general circulation model. Atmos. Ocean. 33 (3), 407-446. doi:10.1080/07055900.1995. 9649539

Zhang, J., Tian, W., Wang, Z., Xie, F., and Wang, F. (2015a). The inuence of ENSO on northern mid-latitude ozone during the winter to spring transition. J. Clim. 28, 4774-4793. doi:10.1175/JCLI-D-14-00615.1

Zhang, J., Tian, W., Xie, F., Li, Y., Wang, F., Huang, J., et al. (2015b). Inuence of the El Niño southern oscillation on the total ozone column and clear-sky ultraviolet radiation over China. Atmos. Environ. 120, 205-216. doi:10.1016/j.atmosenv. 2015.08.080

Conflict of Interest: The authors declare that the research was conducted in the absence of any commercial or financial relationships that could be construed as a potential conflict of interest.

Copyright $\odot 2021$ Zhou, Yan and Luo. This is an open-access article distributed under the terms of the Creative Commons Attribution License (CC BY). The use, distribution or reproduction in other forums is permitted, provided the original author(s) and the copyright owner(s) are credited and that the original publication in this journal is cited, in accordance with accepted academic practice. No use, distribution or reproduction is permitted which does not comply with these terms. 